\title{
Developmental changes in plasma leptin and hypothalamic leptin receptor expression in the rat: peripubertal changes and the emergence of sex differences
}

\author{
J T Smith and B J Waddell \\ School of Anatomy and Human Biology and The Western Australian Institute for Medical Research, The University of Western Australia, \\ 35 Stirling Hwy Crawley, Perth, Western Australia, 6009, Australia \\ (Requests for offprints should be addressed to B Waddell; Email: bwaddell@anhb.uwa.edu.au)
}

\begin{abstract}
Leptin, the peptide hormone product of the ob gene, regulates food intake and energy expenditure at the hypothalamic level via the long-form of the leptin receptor $(\mathrm{Ob}-\mathrm{Rb})$. Leptin also plays a key role in determining the onset of puberty, but there is controversy as to whether leptin provides a trigger for puberty or is a permissive signal. Thus, although leptin administration can advance puberty onset in rodents, circulating leptin appears stable across puberty. While these data suggest a permissive role for leptin in rat puberty, it is possible that a change in hypothalamic response to leptin (e.g. via increased Ob-Rb expression) could enhance leptin action and thus trigger puberty without a rise in circulating leptin. In the present study we assessed developmental changes in hypothalamic $\mathrm{Ob}-\mathrm{Rb} \mathrm{mRNA}$ and protein expression in female and male rats from late fetal to postpubertal life. Quantitative RT-PCR showed that Ob-Rb mRNA increased $(P<0 \cdot 05)$ by around fivefold from fetal to postpubertal life in both females and males. These increases in $\mathrm{Ob}-\mathrm{Rb}$ mRNA expression were gradual, but did not increase significantly between postnatal day 30 (pre-puberty) and
\end{abstract}

day 51 (post-puberty). By day 51, hypothalamic Ob-Rb mRNA expression was higher $(P<0.05)$ in females relative to males. Hypothalamic $\mathrm{Ob}-\mathrm{Rb}$ protein showed a comparable developmental pattern (approximate threefold increase from fetal to postpubertal life), although a significant increase $(15 \% ; P<0 \cdot 05)$ was observed between days 30 and 51 in females. Plasma leptin levels exhibited a dynamic pattern in both male and female rats during the prepubertal period, characterised by a precipitous fall after birth, relative stability to day 5 , then a rapid increase to a transient peak on day 12. Plasma leptin then remained unchanged from day 15 in female rats but increased in males after puberty, thus confirming the well-recognised sex difference in adult rat leptin levels. In conclusion, this study shows that developmental increases occur not only in plasma leptin but also in hypothalamic $\mathrm{Ob}-\mathrm{Rb}$ expression, suggesting that both are likely to influence the timing of puberty onset. Moreover, our data show that sex differences in both hypothalamic $\mathrm{Ob}-\mathrm{Rb}$ and plasma leptin emerge only after puberty.

Journal of Endocrinology (2003) 176, 313-319

\section{Introduction}

Leptin is a $16 \mathrm{kDa}$ peptide hormone product of the ob gene expressed in a variety of tissues, predominantly adipocytes, and acts via its receptor to regulate food intake and energy expenditure at the hypothalamic level (Campfield et al. 1995, Pellymounter et al. 1995). Leptin is also known to act as a metabolic signal to the reproductive system (Cunningham et al. 1999) that, in turn, is regulated by body weight and nutritional status (Barash et al. 1996). As leptin is known to regulate gonadotrophin-releasing hormone secretion (Nagatani et al. 1998) and mutations in the $o b$ gene in mice prevent the attainment of sexual maturity (Zhang et al. 1994), leptin has been proposed as a metabolic signal to the timing of puberty (Cheung et al. 1997). While a contribution of leptin to the timing of normal sexual maturation is clear, there is controversy as to whether leptin per se is a trigger for puberty onset or serves only in a permissive role (Ahima et al. 1997, Chehab et al. 1997, Almog et al. 2001, Cheung et al. 2001). If leptin were a trigger for puberty, an increase in circulating levels would be expected yet this is not universally observed (Gruaz et al. 1998, Matsuda et al. 1999, Cheung et al. 2001, Watanobe \& Schioth 2002). On the other hand, a change in the hypothalamic response to leptin (e.g. via increased expression of the leptin receptor) could potentially enhance leptin action and thus trigger puberty without any change in circulating leptin levels. The leptin receptor is a member of the class I cytokine receptor family, and six multiple splice variants have been identified (for review see Tartaglia 1997). These splice variants fall into three categories: a long form $(\mathrm{Ob}-\mathrm{Rb})$, located 
primarily within the hypothalamus, capable of full signal transduction; a number of C-terminally truncated forms (Ob-Ra, Ob-Rc, Ob-Rd, Ob-Rf), of which Ob-Ra is the most commonly studied and is thought to act as a transporter of leptin; and a soluble receptor $(\mathrm{Ob}-\mathrm{Re})$ that lacks both the intracellular and transmembranous domains and acts as a circulating leptin binding protein. Cheung et al. (2001) recently reported no change in the expression of $\mathrm{Ob}-\mathrm{Rb}$ mRNA in several hypothalamic nuclei measured by in situ hybridisation; the authors suggested, however, that their methodology may lack the sensitivity to detect biologically significant change. In the present study, therefore, we used real-time RT-PCR to quantitate hypothalamic $\mathrm{Ob}-\mathrm{Ra}, \mathrm{Ob}-\mathrm{Rb}$, and $\mathrm{Ob}-\mathrm{Re}$ mRNA expression from fetal to postpubertal life in male and female rats; expression patterns for hypothalamic $\mathrm{Ob}-\mathrm{Rb}$ were also confirmed by Western analysis, and plasma leptin levels were measured over the same period. These analyses enabled determination of the extent of sex differences in plasma leptin and hypothalamic leptin receptor expression. Previous studies indicate that while plasma leptin is clearly higher in adult male compared with female rats (Landt et al. 1998, Pinilla et al. 1999), the developmental emergence of this sex difference remains uncertain, and the possibility that hypothalamic leptin receptor expression differs between males and females has not been explored.

\section{Materials and Methods}

\section{Animals}

Albino Wistar rats aged between 9 and 12 weeks were obtained from the Animals Resources Centre (Murdoch, Australia) and maintained under controlled conditions as previously described (Burton \& Waddell 1994). Rats were mated overnight and the day on which spermatozoa were present in the vaginal smear was designated gestational day 1 (g1). The day of birth, usually g23 in this colony of rats, was designated postnatal day $0(\mathrm{p} 0)$. Pup sex was determined by examination of external genital morphology and litters were standardised to 10 pups before the third day postpartum and, where applicable, were weaned on p30. The onset of puberty in this colony occurs on day 41 in females (vaginal opening) and day 48 in males (preputial separation) (Smith \& Waddell 2000). All procedures involving animals were conducted only after approval by the Animal Experimentation Ethics Committee of The University of Western Australia.

\section{Blood sampling and tissue collection}

For collection of fetal blood and hypothalamus, pregnant rats were anaesthetised at g22 with halothane/nitrous oxide and fetuses were removed. Blood samples from female and male g22, p0, p1, p2, p3, and p5 rats were obtained by decapitation (at g22 and p0, blood samples from 4 fetuses/newborns from each litter were pooled to provide sufficient volume). Blood samples were collected from anaesthetised rats at p9, p12, p15, p20 by decapitation, and at p30 and p51 via the exposed dorsal aorta. Hypothalami were obtained from rats at selected stages (g22, p0, p5, p9, p12, p15, p30, and p51) as previously described (Zakrzewska et al. 1999); briefly, each hypothalamus was dissected from a frontal brain slice between the optic chiasm and the mammillary bodies. Slices extended laterally to the perihypothalamic sulcus and superiorly to the anterior commissure. Hypothalami were immediately frozen in liquid nitrogen for real-time quantitative RTPCR or Western blot analysis.

\section{Radioimmunoassays}

Blood samples collected as described above were centrifuged at 11000 r.p.m. for $5 \mathrm{~min}$ and plasma was stored at $-20{ }^{\circ} \mathrm{C}$ until assayed. Plasma leptin concentrations were measured using a radioimmunoassay kit supplied by Linco Research (St Charles, MO, USA). The intra- and interassay coefficients of variation were $4 \%$ and $8 \%$ respectively.

\section{Real-time quantitative RT-PCR}

Total RNA was isolated from $\mathrm{g} 22$, p12, p30, and p51 hypothalami, reverse transcribed and the resultant cDNA purified and quantified as previously described (Seeber et al. 2002). The cDNA primers to specific rat Ob-Ra, $\mathrm{Ob}-\mathrm{Rb}$ and $\mathrm{Ob}-\mathrm{Re}$ (Takaya et al. 1996) were positioned to span intron-exon junctions to distinguish cDNA from genomic DNA and were as described previously (Smith \& Waddell 2002). External standards were generated from regular PCR products using the $\mathrm{Ob}-\mathrm{Ra}, \mathrm{Ob}-\mathrm{Rb}$, and $\mathrm{Ob}-\mathrm{Re}$ primers as previously described (Smith \& Waddell 2002).

Quantitative PCR and melting curve analyses were performed in $10 \mu \mathrm{l}$ reaction volumes in capillary tubes using the LightCycler system (Roche Diagnostics, Indianapolis, IN, USA) as previously described (Smith \& Waddell 2002). Melting curve analysis showed a single PCR product for each Ob-R isoform and this was confirmed by gel electrophoresis (data not shown). Fluorescence values were analysed and a standard curve constructed using the LightCycler software, and sample values were expressed as fg RNA/ $\mu \mathrm{g}$ cDNA. The intraand interassay coefficients of variation were as follows: Ob-Ra, $0 \cdot 9 \%$ and $1 \cdot 2 \%$; Ob-Rb, $0 \cdot 6 \%$ and $2 \cdot 4 \%$; Ob-Re, $0 \cdot 2 \%$ and $0 \cdot 3 \%$ respectively.

\section{Western blot analysis}

Hypothalami (g22, p0, p5, p9, p12, p15, p30, and p51) were homogenised $(250 \mu \mathrm{l}, 10 \mathrm{mM}$ Tris buffer containing 
$1.5 \mathrm{mM}$ EDTA, $1 \mathrm{mM}$ dithiothreitol, $1 \mathrm{mM}$ phenylmethylsulphonyl fluoride and $100 \mu \mathrm{g} / \mathrm{ml}$ trypsin inhibitor), and then centrifuged at $105000 \times \mathbf{g}$ for $30 \mathrm{~min}$. Supernatant protein $(30 \mu \mathrm{g})$ was resolved by SDS-PAGE (7\% separating) and transferred to nitrocellulose membrane (Hybond C-Super, Amersham Pharmacia Biotech, Sydney, Australia). Consistency of protein loading and transfer among samples was confirmed by Ponceau S dye staining (ICN Biomedicals, Aurora, OH, USA). Membranes were incubated for $1 \mathrm{~h}$ in blocking solution containing 5\% non-fat milk powder, then overnight at $4{ }^{\circ} \mathrm{C}$ with Ob-R antibody (diluted 1:400; Santa Cruz Biotechnology, Santa Cruz, CA, USA). Immunoreactive bands were identified by incubation with horseradish peroxidase conjugate donkey anti-goat secondary antibody (diluted 1:5000, Chemicom International, Temecula, CA, USA) and signals were visualised using a chemiluminescence detection kit (SuperSignal Substrate, Pierce Chemical, Rockford, IL, USA). The resultant autoradiographs were quantified by densitometry using Scion Image analysis software (Release beta 3b; www.scioncorp.com) as previously described (Burton et al. 1998). Because the primary antibody was generated against the common region of the $\mathrm{Ob}-\mathrm{R}$ it theoretically cross-reacts with all three major isoforms; by Western analysis, however, only the $120 \mathrm{kDa} \mathrm{Ob}-\mathrm{Rb}$ isoform (Wang et al. 1998) was detected (see Results).

\section{Statistical analysis}

All data are expressed as means \pm S.E.M. where a minimum of three animals was used for each experimental variable and each litter represented an ' $n$ ' of one. Variation in body weight, plasma leptin concentration, Ob-R mRNA and protein related to age and sex was assessed by one-way or two-way ANOVAs as appropriate. Where the F-test for the ANOVA reached statistical significance $(P<0 \cdot 05)$, differences among specific means were assessed by least significant difference (LSD) test (Snedecor \& Cochran 1989). Comparison of hypothalamic Ob-Rb protein in males and females at day 52 of age was made by unpaired t-test.

\section{Results}

Body weight and plasma leptin concentrations

Body weight varied significantly with both age $(P<0 \cdot 001)$ and sex $(P<0 \cdot 05)$ and there was significant interaction between age and sex $(P<0 \cdot 001$, two-way ANOVA). Specifically, body weights were similar between males and females until post-puberty (p51), when males were significantly heavier $(30 \%, P<0 \cdot 001$, see Fig. 1). Plasma leptin concentrations varied significantly with age in both male and female rats $(P<0.001$, see Fig. 1). The key

\section{Female}
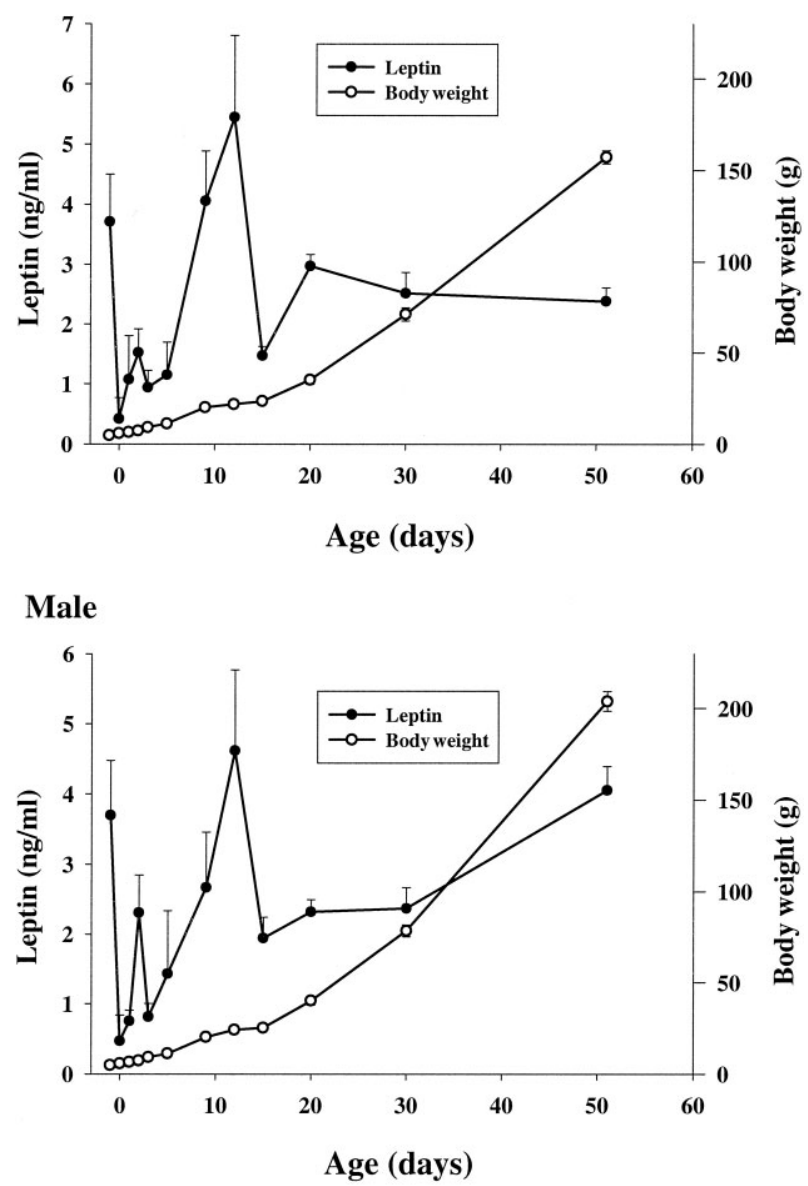

Figure 1 Developmental changes in the concentration of plasma leptin and body weight in female and male rats. Values $(\mathrm{ng} / \mathrm{ml})$ are the mean \pm S.E.M. of $n=3-6$ per group. Body weight results: significant variation occurred with age $(P<0 \cdot 001)$ and sex $(P<0 \cdot 05)$ and there was significant interaction $(P<0 \cdot 001$, two-way ANOVA). Thus, males and females only differed $(P<0 \cdot 001)$ at post-puberty (p51). Leptin results: variation occurred with age $(P<0 \cdot 001)$ in both females $\left(\mathrm{LSD}_{0.05}=2 \cdot 03-2 \cdot 66\right)$ and males $\left(\mathrm{LSD}_{0.05}=1 \cdot 59-2 \cdot 27\right)$; see Results for specific comparisons.

features of this developmental change were that leptin concentrations fell precipitously at birth but then increased $(P<0 \cdot 05)$ after postnatal day 5 to peak at day 12 in both sexes. Plasma leptin then declined markedly by day 15 in males $(P<0 \cdot 05)$ and females $(P<0 \cdot 01)$, and although there appeared to be a subsequent increase in females by day 20 , this was not statistically significant. Thereafter, plasma leptin remained unchanged in females up to post-puberty $(\mathrm{p} 51)$, whereas in males it increased $(P<0 \cdot 05)$ from prepuberty (p30) to post-puberty (p51). Thus, sex differences in plasma leptin became evident only after puberty onset, being more than $40 \%$ lower in females by day 51 $(P<0 \cdot 001)$. 


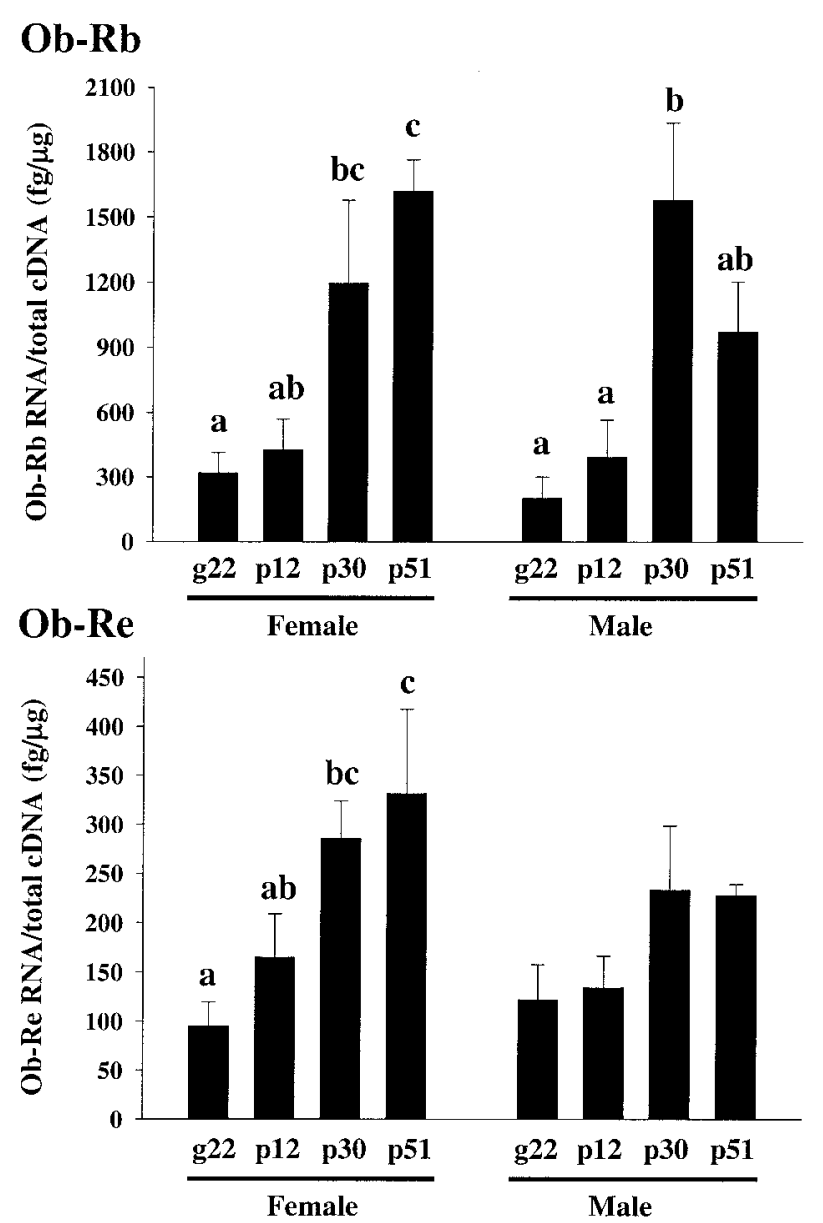

Figure 2 Quantification of hypothalamic Ob-Rb and Ob-Re mRNA at $\mathrm{g} 22, \mathrm{p} 12, \mathrm{p} 30$, and p51 by real-time RT-PCR. Values are expressed as fg RNA/ $\mu \mathrm{g}$ total $\mathrm{CDNA}$ and are the mean \pm S.E.M. of $n=3$ per group. Significant variation with age was detected in Ob-Rb (males, $P<0 \cdot 01$; females, $P<0 \cdot 05$ ). Ob-Re expression also varied $(P<0.05)$ with age in females but not in males. In males and females values without common notations differ significantly $(P<0 \cdot 05$, LSD test).

\section{RT-PCR analysis of hypothalamic leptin receptor $m R N A$ expression}

Hypothalamic expression of $\mathrm{Ob}-\mathrm{Rb}$ mRNA increased with age $(P<0 \cdot 001)$ and there was a significant interaction between age and sex $(P<0 \cdot 05$, two-way ANOVA). Specifically, $\mathrm{Ob}-\mathrm{Rb}$ expression in females increased from postnatal day 12 to peak at post-puberty (p51, P<0.05, one-way ANOVA, see Fig. 2); overall, there was an approximate fivefold increase in $\mathrm{Ob}-\mathrm{Rb} \mathrm{mRNA}$ from fetal to postpubertal life in females. A similar pattern of hypothalamic Ob-Rb mRNA was observed in males, but this expression appeared to fall after puberty and was significantly lower $(P<0 \cdot 05)$ than that in females at day 51 (see Fig. 2). The hypothalamus also expressed Ob-Re mRNA but at a lower level (40 to $80 \%$ less) than that of
Ob-Rb (see Fig. 2), and in females Ob-Re expression increased from late fetal life (g22) to post-puberty ( $\mathrm{p} 51$; $P<0 \cdot 05$, one-way ANOVA). In males, however, $\mathrm{Ob}-$ $\mathrm{Re}$ expression remained unchanged over this period. Hypothalamic expression of $\mathrm{Ob}-\mathrm{Ra}$ mRNA was detected at much lower levels than either Ob-Rb (97-99\% less) or $\mathrm{Ob}-\mathrm{Re}$ and did not change over development (data not shown).

\section{Western blot analysis of $\mathrm{Ob}-\mathrm{R}$ in the hypothalamus}

Consistent with the changes in hypothalamic Ob-Rb mRNA expression, Western analysis showed a clear band of immunoreactivity at $120 \mathrm{kDa}$ corresponding to the Ob-Rb protein (Wang et al. 1998) at all stages examined (see Fig. 3). This Ob-Rb expression increased $(P<0 \cdot 001)$ progressively from a minimum in the fetus (g22) to a maximum at post-puberty (p51) in both sexes. The increase above fetal hypothalamic Ob-Rb levels was first observed at postnatal day 12 (p12) in both sexes $(P<0 \cdot 05)$, and this rise continued between days 30 and 51 in females $(P<0.05)$ but not in males. As a result, $\mathrm{Ob}-\mathrm{Rb}$ protein levels in males were around 20\% lower than those in females by day 51 , although there was no significant overall sex difference evident by two-way ANOVA. However, when additional samples $(n=4$ each) from day 51 males and females were run on a single Western blot, hypothalamic $\mathrm{Ob}-\mathrm{Rb}$ protein was similarly reduced in males $(79 \cdot 4 \pm 7 \cdot 5$ arbitrary units) compared with females $(100 \cdot 0 \pm 3 \cdot 6)$ and in this case the difference did reach statistical significance $(P<0 \cdot 05$, unpaired $t$-test).

\section{Discussion}

In this study we investigated the developmental patterns of hypothalamic $\mathrm{Ob}-\mathrm{Rb}$ expression and plasma leptin levels from fetal to postpubertal life in male and female rats. The major findings were that hypothalamic $\mathrm{Ob}-\mathrm{Rb}$ mRNA expression was relatively low and stable in the fetal and neonatal periods, increased gradually prior to puberty in both sexes, then reached maximal levels after puberty in females. Comparable patterns were observed for hypothalamic $\mathrm{Ob}-\mathrm{Rb}$ protein. With respect to sex differences in the leptin system, our data show that higher levels of plasma leptin in males relative to females become evident only after puberty. At earlier stages of development the distinct neonatal pattern of plasma leptin, characterised by a marked fall at birth followed by a transient peak at day 12 , is similar in males and females. Sex differences in hypothalamic $\mathrm{Ob}-\mathrm{Rb}$ expression also became evident only after puberty, but in this case expression in females exceeded that in males.

The failure of $o b / o b$ mice to undergo sexual maturation underscores the central role of leptin in promoting the onset of puberty (Zhang et al. 1994). Nevertheless, there 

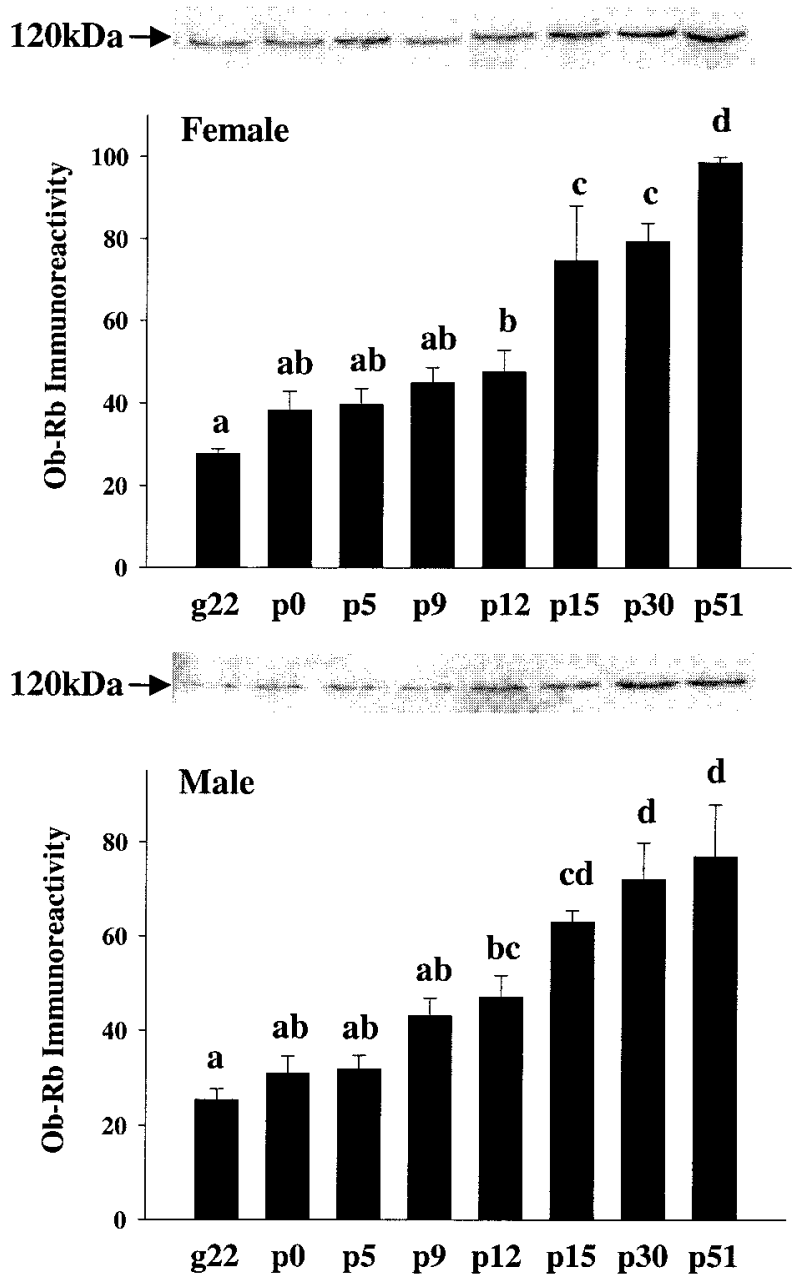

Figure 3 Western blot analysis and quantification of Ob-Rb protein in the rat hypothalamus during development. Values are expressed in arbitrary density units and are the mean \pm S.E.M. of $n=3-6$ per group. Significant variation occurred with age in both males and females (males, $P<0 \cdot 001$; females, $P<0 \cdot 001$ ); values without common notations differ significantly $(P<0 \cdot 05$ LSD test).

has been considerable controversy as to whether leptin serves a permissive or a triggering role in this regard. Thus, administration of exogenous leptin to prepubertal rodents was shown to advance the onset of puberty (Ahima et al. 1997, Chehab et al. 1997, Almog et al. 2001). On the other hand, if leptin were a trigger for normal sexual development, one would expect an increase in circulating leptin levels in the lead up to puberty. Two studies have reported a rise from pre- to post-puberty in rats (Gruaz et al. 1998, Watanobe \& Schioth 2002) whereas others have observed that plasma leptin remains stable across the peripubertal period (Matsuda et al. 1999, Cheung et al. 2001). Our data show an increase in plasma leptin from day 30 (prepubertal) to day 51 (postpubertal) in male but not female rats. In the latter, however, unchanging plasma leptin levels were accompanied by a slight increase in hypothalamic $\mathrm{Ob}-\mathrm{Rb}$ expression from pre- to postpuberty suggesting that females may become more responsive to plasma leptin around the time of puberty. Thus, even though developmental changes in plasma leptin and hypothalamic $\mathrm{Ob}-\mathrm{Rb}$ were relatively minor in the peripubertal period, it remains possible that a threshold level of both is required to induce puberty, and so a triggering role for leptin cannot be entirely ruled out.

The present work also shows for the first time that the well established sex difference in plasma leptin is not present up to at least day 30 , but is clearly evident after puberty (females around $40 \%$ lower than males by day 51 ). Moreover, the higher plasma leptin levels in males are accompanied by slightly lower hypothalamic Ob-Rb expression. The latter observation suggests that after puberty male rats may be less responsive to leptin than females, consistent with the clearly greater body weight and fat mass of adult males (Reed et al. 1930). Interestingly, the postpubertal sex difference of plasma leptin in the rat (male $>$ female) is opposite to that in humans where levels in females clearly exceed those in males (Landt $e t$ al. 1998, Roemmich et al. 1998, Pinilla et al. 1999). Again this presumably reflects the greater percentage body fat in human females relative to males (Roemmich et al. 1998), again possibly related to differences in responsiveness to leptin. Sex differences in both leptin and leptin receptor are likely to reflect the actions and interactions of oestrogen and testosterone, but how such effects are mediated is unclear. It is known that leptin receptor expression in the rat choroid plexus, hypothalamus (Bennett et al. 1999) and ovary (Duggal et al. 2002) are minimal at cycle stages when oestrogen is high, suggestive of oestrogen inhibition of Ob-R expression. On the other hand, hypothalamic $\mathrm{Ob}-\mathrm{Rb}$ expression in the present work was higher in females relative to males, suggesting that the suppressive effect of oestrogen is not central to the observed sex difference in $\mathrm{Ob}-\mathrm{Rb}$. To our knowledge the effects of testosterone on $\mathrm{Ob}-\mathrm{Rb}$ expression have not been investigated. Leptin production also appears to be influenced by sex steroids, since plasma levels are maximal at prooestrus when oestrogen is high (Duggal et al. 2002), and testosterone stimulates leptin secretion by rat epididymal adipose tissue in vitro (Nazian 2001). Interestingly, testosterone does not affect leptin secretion by human omental adipose tissue from either males or females, although leptin secretion was inhibited by dihydrotestosterone and other androgens in females (Pineiro et al. 1999). Therefore, oestrogen and testosterone may interact to regulate leptin production, and their effects may vary among different species and/or fat depots. Further studies are required to determine such interactions and thus the nature of sex differences in plasma leptin and hypothalamic leptin receptor expression. 
A dramatic fall in plasma leptin levels on postnatal day 1 suggests that high leptin levels in the fetus are likely to originate from the mother, since the rat fetus and placenta do not synthesise significant amounts of leptin de novo (Dessolin et al. 1997, Kawai et al. 1997, Amico et al. 1998). A similar postnatal decline in plasma leptin has been observed in newborn humans (Harigaya et al. 1999), consistent with leptin synthesis by the human placenta (Masuzaki et al. 1997). Plasma leptin levels then remained relatively low in the neonate until day 5 before increasing to a transient peak at day 12 , and this pattern was comparable in males and females. A similar neonatal pattern of plasma leptin has been reported in both the rat (Rayner et al. 1997, Matsuda et al. 1999, Morash et al. 2001) and the mouse (Devaskar et al. 1997, Ahima et al. 1998), and a transient peak has also been observed in humans at 3 weeks of age (Harigaya et al. 1999). The present work further shows that neonatal leptin fluctuations occur on a background of stable but relatively low hypothalamic $\mathrm{Ob}-\mathrm{Rb} \mathrm{mRNA}$ and protein expression, consistent with a previous report showing low hypothalamic $\mathrm{Ob}-\mathrm{Rb}$ immunolocalisation in the fetal and neonatal rat (Matsuda et al. 1999). Therefore, the hypothalamus is potentially a leptin target at these early stages of development, and leptin may regulate metabolic rate and food intake as occurs in the adult. If so, the initial fall in plasma leptin at birth would be expected to stimulate food intake during the first days of life, an effect that would appear to be highly adaptive. On the other hand, the subsequent peak at day 12 appears paradoxical given the high energy demands during this period, and so the fetal and neonatal hypothalamus may be relatively insensitive to leptin due to the low $\mathrm{Ob}-\mathrm{Rb}$ expression. Accordingly, leptin administration to neonatal mice and rats fails to influence food intake but does increase metabolic rate (Stehling et al. 1996, Mistry et al. 1999), and neonatal mice subjected to food deprivation show no change in plasma leptin (Ahima et al. 1998). Further studies are required to identify the precise roles of leptin in the neonate and how they might change over the course of development.

Previous studies have reported expression of shorter isoforms of the leptin receptor, $\mathrm{Ob}-\mathrm{Ra}$ and $\mathrm{Ob}-\mathrm{Re}$, in the adult rat hypothalamus (Lollmann et al. 1997), but the present work is the first to quantitate relative expression levels and developmental changes. Interestingly, expression of the soluble isoform, Ob-Re, increased in females during development, but its physiological role is unknown. Given that $\mathrm{Ob}-\mathrm{Re}$ is thought to act as a leptin binding protein in plasma (Gavrilova et al. 1997, Seeber et al. 2002), its increased expression in the hypothalamus during development could influence the dynamics of leptin access to $\mathrm{Ob}-\mathrm{Rb}$.

In conclusion, this study shows a marked developmental increase in hypothalamic leptin receptor expression from late gestation to the prepubertal period. Peripubertal increases were also evident in hypothalamic $\mathrm{Ob}-\mathrm{Rb}$ expression (in females) and plasma leptin (in males), and although these changes were small it remains possible that both contribute to the timing of puberty onset. Our data further show that sex differences in both hypothalamic $\mathrm{Ob}-\mathrm{Rb}$ expression (female $>$ male) and plasma leptin levels (male $>$ female) become evident after puberty.

\section{Acknowledgements}

The authors wish to thank Dr Peter Burton and Ms Sue Hisheh for their expert technical assistance. This work was supported by the National Health and Medical Research Council of Australia (project grant \# 139104). J T S was supported by an Australian Postgraduate Research Award.

\section{References}

Ahima RS, Dushay J, Flier SN, Prabakaran D \& Flier JS 1997 Leptin accelerates the onset of puberty in normal female mice. Journal of Clinical Investigation 99 391-395.

Ahima RS, Prabakaran D \& Flier JS 1998 Postnatal leptin surge and regulation of circadian rhythm of leptin by feeding. Implications for energy homeostasis and neuroendocrine function. Journal of Clinical Investigation 101 1020-1027.

Almog B, Gold R, Tajima K, Dantes A, Salim K, Rubinstein M, Barkan D, Homburg R, Lessing JB, Nevo N, Gertler A \& Amsterdam A 2001 Leptin attenuates follicular apoptosis and accelerates the onset of puberty in immature rats. Molecular and Cellular Endocrinology 183 179-191.

Amico JA, Thomas A, Crowley RS \& Burmeister LA 1998 Concentrations of leptin in the serum of pregnant, lactating, and cycling rats and of leptin messenger ribonucleic acid in rat placental tissue. Life Sciences 63 1387-1395.

Barash IA, Cheung CC, Weigle DS, Ren H, Kabigting EB, Kuijper JL, Clifton DK \& Steiner RA 1996 Leptin is a metabolic signal to the reproductive system. Endocrinology 137 3144-3147.

Bennett PA, Lindell K, Wilson C, Carlsson LM, Carlsson B \& Robinson IC 1999 Cyclical variations in the abundance of leptin receptors, but not in circulating leptin, correlate with NPY expression during the oestrous cycle. Neuroendocrinology 69 417-423.

Burton PJ \& Waddell BJ 1994 11ß-Hydroxysteroid dehydrogenase in the rat placenta: developmental changes and the effects of altered glucocorticoid exposure. Journal of Endocrinology 143 505-513.

Burton PJ, Krozowski ZS \& Waddell BJ 1998 Immunolocalization of $11 \beta$-hydroxysteroid dehydrogenase types 1 and 2 in rat uterus: variation across the estrous cycle and regulation by estrogen and progesterone. Endocrinology 139 376-382.

Campfield LA, Smith FJ, Guisez Y, Devos R \& Burn P 1995 Recombinant mouse $\mathrm{OB}$ protein: evidence for a peripheral signal linking adiposity and central neural networks. Science 269 546-549.

Chehab FF, Mounzih K, Lu R \& Lim ME 1997 Early onset of reproductive function in normal female mice treated with leptin. Science 275 88-90.

Cheung CC, Thornton JE, Kuijper JL, Weigle DS, Clifton DK \& Steiner RA 1997 Leptin is a metabolic gate for the onset of puberty in the female rat. Endocrinology 138 855-858.

Cheung CC, Thornton JE, Nurani SD, Clifton DK \& Steiner RA 2001 A reassessment of leptin's role in triggering the onset of puberty in the rat and mouse. Neuroendocrinology 74 12-21.

Cunningham MJ, Clifton DK \& Steiner RA 1999 Leptin's actions on the reproductive axis: perspectives and mechanisms. Biology of Reproduction $60216-222$. 
Dessolin S, Schalling M, Champigny O, Lonnqvist F, Ailhaud G, Dani C \& Ricquier D 1997 Leptin gene is expressed in rat brown adipose tissue at birth. FASEB Journal 11 382-387.

Devaskar SU, Ollesch C, Rajakumar RA \& Rajakumar PA 1997 Developmental changes in ob gene expression and circulating leptin peptide concentrations. Biochemical and Biophysical Research Communications 238 44-47.

Duggal PS, Weitsman SR, Magoffin DA \& Norman RJ 2002 Expression of the long (OB-RB) and short (OB-RA) forms of the leptin receptor throughout the oestrous cycle in the mature rat ovary. Reproduction 123 899-905.

Gavrilova O, Barr V, Marcus-Samuels B \& Reitman M 1997 Hyperleptinemia of pregnancy associated with the appearance of a circulating form of the leptin receptor. Journal of Biological Chemistry 272 30546-30551.

Gruaz NM, Lalaoui M, Pierroz DD, Englaro P, Sizonenko PC, Blum WF \& Aubert ML 1998 Chronic administration of leptin into the lateral ventricle induces sexual maturation in severely food-restricted female rats. Journal of Neuroendocrinology 10 627-633.

Harigaya A, Onigata K, Nako Y, Nagashima K \& Morikawa A 1999 Role of serum leptin in the regulation of weight gain in early infancy. Biology of the Neonate 75 234-238.

Kawai M, Yamaguchi M, Murakami T, Shima K, Murata Y \& Kishi K 1997 The placenta is not the main source of leptin production in pregnant rat: gestational profile of leptin in plasma and adipose tissues. Biochemical and Biophysical Research Communications $\mathbf{2 4 0}$ 798-802.

Landt M, Gingerich RL, Havel PJ, Mueller WM, Schoner B, Hale JE \& Heiman ML 1998 Radioimmunoassay of rat leptin: sexual dimorphism reversed from humans. Clinical Chemistry 44 565-570.

Lollmann B, Gruninger S, Stricker-Krongrad A \& Chiesi M 1997 Detection and quantification of the leptin receptor splice variants $\mathrm{Ob}-\mathrm{Ra}, \mathrm{b}$, and, e in different mouse tissues. Biochemical and Biophysical Research Communications 238 648-652.

Masuzaki H, Ogawa Y, Sagawa N, Hosoda K, Matsumoto T, Mise H, Nishimura H, Yoshimasa Y, Tanaka I, Mori T \& Nakao K 1997 Nonadipose tissue production of leptin: leptin as a novel placenta-derived hormone in humans. Nature Medicine $\mathbf{3}$ 1029-1033.

Matsuda J, Yokota I, Tsuruo Y, Murakami T, Ishimura K, Shima K \& Kuroda Y 1999 Developmental changes in long-form leptin receptor expression and localization in rat brain. Endocrinology 140 5233-5238.

Mistry AM, Swick A \& Romsos DR 1999 Leptin alters metabolic rates before acquisition of its anorectic effect in developing neonatal mice. American Journal of Physiology 277 R742-R747.

Morash B, Wilkinson D, Murphy P, Ur E \& Wilkinson M 2001 Developmental regulation of leptin gene expression in rat brain and pituitary. Molecular Cellular Endocrinology 185 151-159.

Nagatani S, Guthikonda P, Thompson RC, Tsukamura H, Maeda KI \& Foster DL 1998 Evidence for GnRH regulation by leptin: leptin administration prevents reduced pulsatile LH secretion during fasting. Neuroendocrinology 67 370-376.

Nazian SJ 2001 Leptin secretion from the epididymal fat pad is increased by the sexual maturation of the male rat. Journal of Andrology 22 491-496.

Pelleymounter MA, Cullen MJ, Baker MB, Hecht R, Winters D, Boone T \& Collins F 1995 Effects of the obese gene product on body weight regulation in $o b / o b$ mice. Science $269540-543$.
Pineiro V, Casabiell X, Peino R, Lage M, Camina JP, Menendez C, Baltar J, Dieguez C \& Casanueva F 1999 Dihydrotestosterone, stanozolol, androstenedione and dehydroepiandrosterone sulphate inhibit leptin secretion in female but not in male samples of omental adipose tissue in vitro: lack of effect of testosterone. Journal of Endocrinology 160 425-432.

Pinilla L, Seoane LM, Gonzalez L, Carro E, Aguilar E, Casanueva FF \& Dieguez C 1999 Regulation of serum leptin levels by gonadal function in rats. European Journal of Endocrinology 140 468-473.

Rayner DV, Dalgliesh GD, Duncan JS, Hardie LJ, Hoggard N \& Trayhurn P 1997 Postnatal development of the ob gene system: elevated leptin levels in suckling $f a / f a$ rats. American Journal of Physiology 273 R446-R450.

Reed LL, Yamaguchi F, Anderson WE \& Mendel LB 1930 Factors influencing the distribution and character of adipose tissue in the rat. Journal of Biological Chemistry 87 147-174.

Roemmich JN, Clark PA, Berr SS, Mai V, Mantzoros CS, Flier JS, Weltman A \& Rogol AD 1998 Gender differences in leptin levels during puberty are related to the subcutaneous fat depot and sex steroids. American Journal of Physiology 275 E543-E551.

Seeber RM, Smith JT \& Waddell BJ 2002 Plasma leptin-binding activity and hypothalamic leptin receptor expression during pregnancy and lactation in the rat. Biology of Reproduction $\mathbf{6 6}$ $1762-1767$.

Smith JT \& Waddell BJ 2000 Increased fetal glucocorticoid exposure delays puberty onset in postnatal life. Endocrinology 414 2422-2428.

Smith JT \& Waddell BJ 2002 Leptin receptor expression in the rat placenta: changes in $\mathrm{Ob}-\mathrm{Ra}, \mathrm{Ob}-\mathrm{Rb}$, and $\mathrm{Ob}-\mathrm{Re}$ with gestational age and suppression by glucocorticoids. Biology of Reproduction $\mathbf{6 7}$ $1204-1210$.

Snedecor GW \& Cochran WG 1989 Statistical Methods, edn 8. Ames, USA: Iowa State University Press.

Stehling O, Doring H, Ertl J, Preibisch G \& Schmidt I 1996 Leptin reduces juvenile fat stores by altering the circadian cycle of energy expenditure. American Journal of Physiology 271 R1770-R1774.

Takaya K, Ogawa Y, Isse N, Okazaki T, Satoh N, Masuzaki H, Mori K, Tamura N, Hosoda K \& Nakao K 1996 Molecular cloning of rat leptin receptor isoform complementary DNAs - identification of a missense mutation in Zucker fatty $(\mathrm{fa} / \mathrm{fa})$ rats. Biochemical and Biophysical Research Communications 225 75-83.

Tartaglia LA 1997 The leptin receptor. Journal of Biological Chemistry 272 6093-6096.

Wang MY, Koyama K, Shimabukuro M, Newgard CB \& Unger RH 1998 OB-Rb gene transfer to leptin-resistant islets reverses diabetogenic phenotype. PNAS 95 714-718.

Watanobe H \& Schioth HB 2002 Postnatal profile of plasma leptin concentrations in male and female rats: relation with the maturation of the pituitary-gonadal axis. Regulatory Peptides 105 23-28.

Zakrzewska KE, Cusin I, Stricker-Krongrad A, Boss O, Ricquier D, Jeanrenaud B \& Rohner-Jeanrenaud F 1999 Induction of obesity and hyperleptinemia by central glucocorticoid infusion in the rat. Diabetes 48 365-370.

Zhang Y, Proenca R, Maffei M, Barone M, Leopold L \& Friedman JM 1994 Position cloning of the mouse obese gene and its human homologue. Nature 372 425-432.

Received 7 November 2002

Accepted 18 November 2002 